
ra 26: 393-397.

\title{
Sazonalidade na produção de raízes e teor de $\beta$-ecdisona em acessos de fáfia
}

\author{
Cirino Corrêa Júnior¹; Lin Chau Ming²; Diógenes Aparício G Cortez \\ ${ }^{1}$ EMATER-PR, C. Postal 1662, 80035-270 Curitiba-PR; 2UNESP-FCA, Produção Vegetal, C. Postal 237, 18603-970 Botucatu-SP;

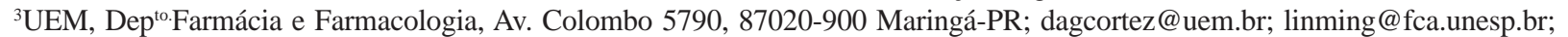 \\ plamed@pr.gov.br
}

\section{RESUMO}

As raízes de espécies de Pfaffia são utilizadas há muito na medicina popular no Brasil, especialmente como tônicas, afrodisíacas e antidiabéticas. Nas margens e ilhas do Rio Paraná, vegeta naturalmente a espécie Pfaffia glomerata (Spreng.) Pedersen, que corre risco de extinção pela coleta intensiva de suas raízes. Para preservála, é preciso desenvolver sistemas que permitam seu uso sustentável. Nesse contexto, foi avaliada a sazonalidade da produção de biomassa e o teor de $\beta$-ecdisona em raízes de diferentes acessos de $P$. glomerata. A coleta dos acessos foi realizada ao longo dos rios Paraná (A1 e A3), Ivaí (A2) e Paranapanema (A4). Mudas produzidas a partir desses acessos foram plantadas experimentalmente em área de ocorrência natural da espécie. O delineamento utilizado foi blocos casualizados, com parcelas subdivididas (acessos nas parcelas; épocas de colheita nas subparcelas), quatro repetições e subparcelas com seis plantas na área útil. Foram realizadas quatro colheitas: oito, dez, doze e quatorze meses após o plantio. As maiores produtividades em massa seca (MS) de raízes foram alcançadas na terceira colheita, com 38,41 g planta-1 ${ }^{-1}$ Já o acesso A4 foi significativamente mais produtivo que os demais, tanto para massa fresca $\left(94,67 \mathrm{~g}\right.$ planta ${ }^{-}$ $\left.{ }^{1}\right)$, quanto para MS de raízes $\left(26,39 \mathrm{~g} \mathrm{planta}^{-1}\right)$. A relação MF/MS das raízes, com média de $26,9 \%$ (3,7:1), foi pouco influenciada pela origem dos acessos, embora tenha se alterado significativamente ao longo das colheitas (de 4,1:1, na primeira colheita, a 3,3:1, na terceira colheita, que correspondeu ao valor máximo). $O$ teor de $\beta$-ecdisona foi estatisticamente similar nas três primeiras colheitas, variando de 0,26 a $0,38 \%$, com redução drástica na última colheita $(0,16 \%)$. Os acessos A2 e A3 foram aqueles com teor de $\beta$-ecdisona mais altos, respectivamente 0,36 e $0,30 \%$. Considerando os resultados obtidos, sugere-se que a terceira colheita, que corresponde a doze meses após o transplante, como a mais adequada para colheita das raízes.

Palavras-chave: Pfaffia glomerata (Spreng.) Pedersen, ginseng, ginseng-brasileiro, biomassa, princípio ativo, plantas medicinais.

\begin{abstract}
Seasonal variation in root production and $\beta$-ecdisone content in pfaffia accessions
\end{abstract}

Roots of Pfaffia sp. are used in the Brazilian popular medicine, especially for their tonic, aphrodisiac, and anti-diabetic properties. Sides and islands of the Paraná River are the natural habitat of $P$. glomerata (Spreng.) Pedersen, a species threatened due to intensive harvests. Therefore, its preservation demands the development of sustainable exploitation systems. In this framework, the seasonal variation of root biomass production and $\beta$-ecdisone contents were evaluated, using different Pfaffia glomerata accessions. Accessions were collected along the rivers Paraná (A1 and A3), Ivaí (A2), and Paranapanema (A4). Plantlets obtained out of these accessions were transplanted to its natural habitat, in a complete random blocks experimental design, with split-plots (accessions in the plots; harvests in the split-plots), and four six-plant replications. Four root harvests took place: at the eighth (May), tenth (July), twelfth (October), and fourteenth (December) month after planting. The highest root yield, assessed as dry mass, was found in the third harvest, $38.41 \mathrm{~g} \mathrm{plant}^{-1}$. Accession A4 significantly outyielded the others, both in root fresh (94.67 $\left.\mathrm{g} \mathrm{plant}^{-1}\right)$ and dry mass $\left(26.39 \mathrm{~g} \mathrm{plant}^{-1}\right)$ yield. The ratio root fresh:dry mass, with an average of $26.91 \%$ (3.7:1), suffered little influence of accession origin. However, it was significantly altered along harvests (from 4.1:1, in the first harvest, to 3.3:1, in the third harvest, where it reached its peak). $\beta$-ecdisone content in roots was similar in the first three harvests, ranging from 0.26 to $0.38 \%$, but with a sharp drop in the last harvest $(0.16 \%)$. Accessions A2 and A3 had the highest $\beta$-ecdisone contents in roots, respectively 0.36 and $0.30 \%$. Taking into account the results obtained in this work, we suggest the third harvest, twelve months after planting, as the most adequate for harvesting pfaffia roots.

Keywords: Pfaffia glomerata (Spreng.) Pedersen, yield, suma, ginseng, active principle, medicinal plant.

\section{(Recebido para publicação em 4 de novembro de 2006; aceito em 29 de julho de 2008)}

$\mathrm{O}$ Brasil é um dos países que possui maior biodiversidade no mundo e a população brasileira tem grande tradição no uso da flora para atender suas necessidades básicas em saúde. Porém, o fornecimento de matéria-prima derivada de plantas medicinais está em risco. As áreas onde estas plantas se desenvolvem naturalmente estão cada vez mais reduzidas pelas pressões exercidas pelo desmatamento, agricultura e urbanização, entre outros (Garcia, 2000).
Não existe área cultivada suficiente para atender toda a demanda. Os coletores de plantas medicinais desconhecem ou ignoram a legislação ambiental pertinente, bem como os consumidores intermediários e finais. Menor ainda é a consciência sobre as implicações da coleta de plantas nativas sobre a base genética de uma espécie e sobre a biodiversidade em geral. Todos estes fatos têm colocado em risco as espécies mais populares para consumo e de bai- xa ocorrência em ambientes naturais, como é o caso da fáfia.

A fáfia é utilizada há séculos pelos índios brasileiros na cura e prevenção de doenças e estudos recentes têm confirmado a sua eficiência (Nishimoto $e t$ al., 1984; Nashimoto et al., 1990; Shiobara et al., 1993). As raízes de espécies do gênero Pfaffia são usadas na medicina popular no Brasil, especialmente como tônicas, afrodisíacas e antidiabéticas. Estas espécies, conheci- 
das popularmente como ginseng-brasileiro e, internacionalmente, como suma, despertaram a atenção de povos asiáticos e europeus e vêm sendo exportadas em quantidades cada vez maiores. Estima-se que nos últimos sete anos o consumo tenha aumentado entre 15 e $17 \%$ ao ano (Corrêa Júnior et al., 2002). São conhecidas por ginseng-brasileiro, principalmente a Pfaffia glomerata (Spreng.) Pedersen, $P$. paniculata Kuntze e a $P$. iresinoides (H.B.K.) Sprengel, cujos estudos fitoquímicos e farmacológicos já estão bastante avançados.

Entre os princípios ativos das raízes de fáfia está a $\beta$-ecdisona, ecdisteróide encontrado em diversas variedades de samambaias, presentes nas gimnospermas e angiospermas. Hormônios de muda análogos a esta classe estão presentes também em insetos e são utilizados na agricultura como inseticidas e, também, na cosmética e na medicina. como os antitumorais (Dinan, 2001; Vigo, 2004).

Nas margens e ilhas do Rio Paraná, entre os estados de São Paulo, Mato Grosso do Sul e Paraná, vegeta naturalmente a Pfaffia glomerata (Spreng.) Pedersen (Smith \& Downs, 1998). Esta espécie corre risco de extinção pela coleta intensiva de suas raízes. Atualmente há consenso entre cientistas, indústrias e organizações ambientalistas de que uma das iniciativas para reduzir a pressão sobre o ambiente e preservar os recursos genéticos é o desenvolvimento de sistemas que permitam o uso sustentável das espécies exploradas. Isto pode ser obtido através de manejo ou diversos tipos de sistemas agro-florestais e do cultivo com base em pesquisas agronômicas, com o objetivo de produzir matéria-prima com qualidade e em quantidade.

Neste contexto, realizou-se um estudo sobre a sazonalidade na produção de raízes e no teor de $\beta$-ecdisona do ginseng-brasileiro (Pfaffia glomerata), cultivado em seu ambiente de ocorrência natural, em um trecho da planície de inundação do alto rio Paraná.

\section{MATERIAL E MÉTODOS}

A coleta dos acessos foi realizada em maio de 2000. Os pontos de coleta fo- ram selecionados em função da área de ocorrência natural da espécie, sendo o acesso 1 na Ilha de Santa Terezinha, PR (A1); acesso 2 em Querência do Norte, PR (A2); acesso 3 em Taquaruçu, MS (A3) e; acesso 4 em Rosana, SP (A4). Nestes locais foram coletados raízes e colo de plantas. O material coletado foi identificado e levado para o viveiro para preparo das mudas. Para a análise das características físico-químicas do solo, foram coletadas amostras compostas das áreas de coleta dos acessos e da área experimental, na camada de 0 a $20 \mathrm{~cm}$. As amostras foram acondicionadas em sacos plásticos, identificados e enviadas ao laboratório de análises do solo da UNESP-Botucatu (Tabela 1).

$\mathrm{O}$ experimento no campo foi instalado no assentamento Pontal do Tigre ADECON 4, município de Querência do Norte, PR, localizado na parte média do Alto Rio Paraná, tendo como limites as longitudes de $53^{\circ} 16^{\prime}$ a $53^{\circ} 25^{\prime}$ ' W e latitudes de $22^{\circ} 43^{\prime}$ a $22^{\circ} 51^{\prime}$ S. A área experimental situou-se dentro da região de maior ocorrência natural da fáfia. $\mathrm{O}$ experimento foi conduzido no período de setembro 2000 a dezembro de 2001. As atividades em laboratório foram realizadas até dezembro de 2002, no laboratório de Farmacognosia da Universidade Estadual de Maringá (UEM) e no laboratório de Soluções Tecnológicas do Instituto de Tecnologia do Paraná (TECPAR). Os dados climáticos foram obtidos junto à estação 23055226 do Sistema Meteorológico do Paraná, localizada em Paranavaí, PR. Em 2000 e 2001, as temperaturas médias foram, respectivamente, $21,9^{\circ} \mathrm{C}$ e $22,2^{\circ} \mathrm{C}$; as médias das máximas foram $28,1^{\circ} \mathrm{C}$ e $28,3^{\circ} \mathrm{C}$ e, as médias das mínimas, $17,2^{\circ} \mathrm{C}$ e $17,8^{\circ} \mathrm{C}$. A precipitação média, em 2000, foi de $1.584 \mathrm{~mm}$ e, em 2001, 1.467 mm. A média anual da umidade relativa do ar, em 2000, foi $75,1 \%$ e, em 2001, 76,2\%. O solo em que foi realizado o experimento foi classificado como Gleissolo Melânico Ta Distrófico hístico, textura argilosa, fase relevo plano mal e muito mal drenado. Já o solo onde foram coletados os acessos foi classificado como Gleissolo Melânico Ta Distrófico típico, textura argilosa, fase relevo plano mal drenado (EMBRAPA, 1999).
O preparo das mudas foi realizado em maio de 2000 no Viveiro Municipal de Querência do Norte, PR. Os propágulos foram preparados cortandose o colo das plantas em pedaços de 9 a 12 g (Oliveira, 1998). Em seguida fezse uma desinfecção do material mergulhando-o em água com $1 \%$ de hipoclorito de sódio durante $30 \mathrm{minu}$ tos. Os propágulos foram colocados em sacos plásticos pretos de 8 x $25 \mathrm{~cm}$, com um substrato composto de solo, esterco de gado e vermiculita, na proporção de 3:1:1, respectivamente, e cobertos com $5 \mathrm{~cm}$ do mesmo substrato. As embalagens assim preparadas foram levadas para canteiros e irrigadas diariamente sempre que não havia precipitação natural. O inicio da brotação ocorreu 16 dias após plantio. A área experimental foi preparada com uma aração e duas gradagens e, em seguida, cercada com seis fios de arame farpado. Não foi realizada adubação de plantio, pois o experimento visou verificar o desenvolvimento da cultura nas condições de fertilidade natural da região (Tabela 1a e 1b), área de ocorrência natural da fáfia.

O delineamento utilizado foi blocos casualizados, com parcelas subdivididas e quatro repetições. Os tratamentos corresponderam aos quatro acessos (A1 a A4) e às quatro épocas de colheita (E1 a E4), descritas adiante. Às parcelas foram alocados os acessos e, às subparcelas, as épocas de colheita. Cada subparcela contou com seis plantas úteis. Em torno da cada bloco e cada parcela foi plantada uma linha de bordadura. $\mathrm{O}$ espaçamento entre os blocos foi de 3,0 m. O espaçamento utilizado nas parcelas foi de $1,0 \mathrm{~m}$ entre linhas e $0,5 \mathrm{~m}$ entre plantas. A área total foi de $768 \mathrm{~m}^{2}$. O plantio definitivo das mudas no campo foi realizado em setembro de 2000. Foram realizadas, em média, duas capinas manuais por mês. A área não foi irrigada, pois houve a intenção de realizar o experimento nas condições edafoclimáticas da região.

A primeira colheita de raízes foi realizada em maio de 2001 (final do outono), oito meses após a instalação do experimento em campo. As colheitas seguintes foram realizadas em intervalos de dois meses: a segunda colheita, em julho de 2001 (inverno); a terceira, em 
Tabela 1. Características químicas e físicas do solo da área de coleta dos acessos de fáfia e da área experimental, na camada de 0 a $20 \mathrm{~cm}$ (chemical and physical properties of the soil from the area where pfaffia accessions were collected and of the experimental area, at $0-20 \mathrm{~cm}$ layer). Botucatu, UNESP, 2003.

\begin{tabular}{|c|c|c|c|c|c|c|c|c|c|c|c|c|c|c|c|}
\hline \multirow{2}{*}{ Local } & \multirow{2}{*}{$\begin{array}{c}\mathrm{pH} \\
\mathrm{CaCl}_{2}\end{array}$} & \multirow{2}{*}{$\begin{array}{l}\text { M.O. } \\
\text { g/dm }\end{array}$} & \multirow{2}{*}{$\begin{array}{c}\mathbf{P} \\
\text { resina } \\
\mathrm{Mg} / \mathrm{dm}^{3}\end{array}$} & $\mathrm{H}+\mathrm{Al}$ & $\mathrm{K}$ & $\mathrm{Ca}$ & Mg & SB & стс & V\% & Boro & Cobre & Ferro & Manganês & Zinco \\
\hline & & & & \multicolumn{7}{|c|}{$\mathrm{mmol} \mathrm{dm}^{-3}$} & \multicolumn{5}{|c|}{$\mathrm{mg} \mathrm{dm}^{-3}$} \\
\hline Acesso 1 & 4,4 & 18 & 9 & 36 & 1,8 & 17 & 4 & 23 & 59 & 39 & 0,12 & 6,2 & 133 & 29,6 & 1,8 \\
\hline Acesso 2 & 4,2 & 10 & 3 & 29 & 0,8 & 6 & 1 & 8 & 37 & 21 & 0,08 & 0,8 & 99 & 3,8 & 0,4 \\
\hline Acesso 3 & 4,2 & 23 & 20 & 93 & 2,2 & 12 & 2 & 16 & 109 & 15 & 0,11 & 3,9 & 147 & 8,8 & 1,4 \\
\hline Acesso 4 & 4,2 & 97 & 50 & 175 & 1,8 & 25 & 7 & 34 & 209 & 16 & 0,22 & 0,4 & 496 & 5,1 & 0,1 \\
\hline $\begin{array}{l}\text { Área } \\
\text { experimental }\end{array}$ & 4,4 & 15 & 1 & 34 & 1,0 & 12 & 6 & 19 & 53 & 36 & 0,15 & 2,8 & 28 & 3,4 & 0,7 \\
\hline
\end{tabular}

Classe textural $=$ argilosa

outubro de 2001 (primavera) e; a última, em dezembro de 2001 (final da primavera), todas no período da manhã. Em cada uma das épocas estabelecidas, realizou-se a colheita das seis plantas centrais de cada subparcela. As raízes foram lavadas com água e escova e colocadas sobre mesas para escorrimento da água superficial. No laboratório da UEM as raízes foram pesadas (massa fresca) e depois trituradas em moinho de faca. O material triturado foi acondicionado em sacos de papel e seco em secador com circulação de ar, a $60 \pm 4^{\circ} \mathrm{C}$, até peso constante. $\mathrm{O}$ tempo médio de secagem foi 36 horas. Em seguida determinou-se a massa seca de cada amostra.

Após a secagem, os sacos de papel tipo Kraft contendo as amostras foram colocados em sacos de plástico atóxico e armazenados em ambiente escuro, arejado e seco. Posteriormente as raízes de cada amostra foram moídas e foram preparados os extratos no Laboratório do Departamento de Farmácia e Bioquímica da Universidade Estadual de Maringá (UEM). O extrato foi preparado reunindo-se o material seco das seis plantas de cada subparcela em uma amostra composta homogeneizada. Desta amostra foram retirados $5 \mathrm{~g}$ de pó, que foram submetidos à extração com extrato clorofórmico em um extrator Soxhlet de $125 \mathrm{~mL}$, durante quatro horas. O solvente foi evaporado e o extrato seco foi armazenado em freezer a $-20^{\circ} \mathrm{C}$.

A determinação do teor de $\beta$ ecdisona foi realizada no Instituto de Tecnologia do Paraná (TECPAR), Departamento de Soluções Tecnológicas. A determinação foi feita por Cromatografia Líquida de Alta Eficiên- cia (CLAE). As amostras para injeção foram preparadas tomando-se $1 \mathrm{mg}$ do extrato seco de cada amostra e diluindo-o em $2 \mathrm{~mL}$ de metanol com auxílio de ultra-som. Em seguida, adicionou-se $2 \mathrm{~mL}$ de água destilada. A suspensão foi filtrada em filtro Millex e $50 \mathrm{~mL}$ desta solução foram injetadas no aparelho para CLAE. As análises por CLAE foram realizadas nas seguintes condições: aparelho Hewlett Packard série 1100 equipado com detector de Diode Array (DAD), injetor automático, bomba quaternária de solventes, coluna cromatográfica: MetaSil $5 \mathrm{~mm}$ ODS 150X4,6 mm, utilizando como fase móvel metanol/água (4:6); fluxo: 1,0 mL $\mathrm{min}^{-1}$ e volume de injeção $50 \mathrm{~mL}$. Para determinar a curva de calibração foram preparadas soluções-padrão com $\beta$ ecdisona Sigma ${ }^{\circledR}$ em metanol (Corrêa Júnior, 2003).

Os valores obtidos para biomassa e teor de $\beta$-ecdisona foram submetidos à análise de variância. A comparação de médias foi feita pelo teste de Tukey, a $1 \%$ de probabilidade.

\section{RESULTADOS E DISCUSSÄO}

Houve diferenças significativas entre acessos de fáfia e entre épocas de colheita tanto para massa fresca, quanto para massa seca de raízes (Tabela 2). Para ambas as características, rendimento significativamente superior foi alcançado na terceira e quarta colheitas (12 e 14 meses após o transplante). Neste caso, é recomendável que a colheita seja realizada doze meses após o transplante, já que, a partir desta época não haveria perda expressiva de produtividade, além de haver menor tempo de ocupação do solo. O acesso A4, coletado em Rosana (SP) destacou-se dos demais, superando em 44,0, 24,7 e 35,3\% a produção de massa fresca de raízes dos acessos A1 (Ilha de Santa Terezinha, PR), A2 (Querência do Norte, PR) e A3 (Taquaruçu, MS), respectivamente, que não diferiram entre si. Em relação à massa seca, o rendimento do acesso A4 superou em 44,9, 31, 3 e $38,2 \%$ os rendimentos dos acessos A1, A2 e A3, respectivamente.

No presente experimento, a produtividade de raízes obtida doze meses após o plantio foi de $1.211 \mathrm{~kg} \mathrm{ha}^{-1}$. Esta produtividade é inferior à relatada por Magalhães (2000), que obteve $1.900 \mathrm{~kg}$ ha $^{-1}$ de raízes secas e também inferior às observações realizadas na área experimental da EMATER-Paraná onde, doze meses após o plantio, a produtividade média foi de $2.013 \mathrm{~kg} \mathrm{ha}^{-1}$ (Corrêa Júnior et al., 2003). A baixa produtividade obtida é atribuída à baixa fertilidade natural do solo da região onde foi instalado o experimento e ao fato de, propositadamente, não ter sido feita nenhuma adubação, enquanto ambas as áreas experimentais dos trabalhos citados apresentaram boa fertilidade. É interessante observar ainda que, segundo a prática dos coletores da região, o colo das plantas também é comercializado (Corrêa Júnior et al., 2006). Esta parte da planta não foi objeto das avaliações de peso, mas determinou-se que os colos representam, em média, $31 \%$ da parte colhida (colo mais raízes), considerando massa seca.

Além disso, é importante considerar a variação que houve entre os aces- 
Tabela 2. Massa de matéria fresca, seca, razão peso fresco/peso seco, teor e produção de $\beta$ ecdisona em raízes de acessos de fáfia, em diferentes épocas de colheita (fresh and dry weight, ration fresh:dried weight, and $\beta$-ecdisone content and yield in roots of pfaffia accessions, in different harvests). Botucatu, UNESP, 2003.

\begin{tabular}{|c|c|c|c|c|}
\hline \multirow{2}{*}{$\begin{array}{l}\text { Épocas de } \\
\text { colheita }^{2}\end{array}$} & \multicolumn{4}{|c|}{ Acessos $^{1}$} \\
\hline & A1 & A2 & A3 & A4 \\
\hline & \multicolumn{4}{|c|}{ Massa de matéria fresca de raízes (g planta-1) } \\
\hline E1 & $48,2 \mathrm{bA}$ & $41,3 \mathrm{cA}$ & $52,0 \mathrm{cA}$ & $60,9 b A$ \\
\hline E2 & $52,4 \mathrm{bB}$ & $46,4 \mathrm{cB}$ & $45,8 \mathrm{cB}$ & $64,5 b A$ \\
\hline E3 & $74,8 \mathrm{aC}$ & $95,9 b B$ & $77,5 b \mathrm{~b}$ & $125,1 \mathrm{aA}$ \\
\hline \multirow[t]{2}{*}{ E4 } & $75,9 a \mathrm{~B}$ & $119,8 \mathrm{aA}$ & $103,6 \mathrm{aA}$ & $128,1 \mathrm{aA}$ \\
\hline & \multicolumn{4}{|c|}{ Massa de matéria seca de raízes (g planta-1) } \\
\hline E1 & $12,0 \mathrm{cA}$ & $09,8 \mathrm{bA}$ & $12,4 \mathrm{bA}$ & $15,1 \mathrm{bA}$ \\
\hline E2 & $14,4 \mathrm{cB}$ & $12,9 b B$ & $12,4 b B$ & $18,5 \mathrm{bA}$ \\
\hline E3 & $22,4 \mathrm{aC}$ & $28,0 \mathrm{aB}$ & $22,8 \mathrm{aC}$ & $38,4 a A$ \\
\hline \multirow[t]{2}{*}{ E4 } & $18,3 \mathrm{bB}$ & $29,6 a A$ & $23,9 a \mathrm{a}$ & $33,5 a A$ \\
\hline & \multicolumn{4}{|c|}{ Relação PF/PS } \\
\hline E1 & $4,0: 1 \mathrm{aA}$ & $4,2: 1 \mathrm{aA}$ & $4,2: 1 \mathrm{aA}$ & $4,0: 1 \mathrm{aA}$ \\
\hline E2 & $3,6: 1 \mathrm{bA}$ & $3,6: 1 b A$ & $3,7: 1 \mathrm{bA}$ & $3,5: 1 b A$ \\
\hline E3 & $3,3: 1 \mathrm{cB}$ & $3,4: 1 \mathrm{cA}$ & $3,4: 1 \mathrm{bA}$ & $3,3: 1 b B$ \\
\hline \multirow[t]{2}{*}{ E4 } & $4,2: 1 \mathrm{aA}$ & $4,0: 1 \mathrm{aA}$ & $4,4: 1 \mathrm{aA}$ & $3,8: 1 \mathrm{aA}$ \\
\hline & \multicolumn{4}{|c|}{ Teor de $\beta$-ecdisona (\%) } \\
\hline $\mathrm{E} 1$ & $0,22 \mathrm{aC}$ & $0,61 \mathrm{aA}$ & $0,32 \mathrm{bB}$ & $0,36 \mathrm{aB}$ \\
\hline E2 & $0,31 \mathrm{aA}$ & $0,30 \mathrm{bA}$ & $0,34 \mathrm{bA}$ & $0,219 \mathrm{bB}$ \\
\hline E3 & $0,327 a A$ & $0,35 b A$ & $0,45 a A$ & $0,40 \mathrm{aA}$ \\
\hline \multirow[t]{2}{*}{ E4 } & $0,13 a B$ & $0,219 \mathrm{cA}$ & $0,109 \mathrm{cB}$ & $0,109 \mathrm{bB}$ \\
\hline & \multicolumn{4}{|c|}{ Produção de $\beta$-ecdisona (g planta-1) } \\
\hline E1 & $0,0327 b B$ & $0,060 \mathrm{bA}$ & $0,040 \mathrm{bB}$ & $0,055 b A$ \\
\hline E2 & $0,044 a A$ & $0,040 \mathrm{bA}$ & $0,042 b A$ & $0,035 b A$ \\
\hline E3 & $0,060 \mathrm{aB}$ & $0,099 a B$ & $0,102 \mathrm{aB}$ & $0,154 a A$ \\
\hline E4 & $0,025 b B$ & $0,056 \mathrm{bA}$ & $0,022 \mathrm{cB}$ & $0,028 b B$ \\
\hline
\end{tabular}

Médias seguidas pela mesma letra minúscula na coluna e maiúscula na linha, dentro de cada característica, não diferem significativamente entre si, teste de Scott-Knott, p<0,05 (means followed by same small letter in the column and capital letter in the row, within each characteristic, did not differ from each other, Scoott-Knott test, $\mathrm{p}<0.05)$; ${ }^{1} / \mathrm{A} 1$ : acesso coletado na Ilha de Santa Terezinha, PR (accession collected at the Santa Terezinha island, PR); A2: acesso coletado em Querência do Norte, PR (accession collected at Querência do Norte, PR); A3: acesso coletado em Taquaruçu, MS (accession collected at Taquaruçu, MS); and A4: acesso coletado em Rosana, SP (accession collected at Rosana, SP); ${ }^{2} / \mathrm{E} 1$ : colheita realizada oito meses após o plantio (harvested eigth months after planting); E2: colheita realizada dez meses após o plantio (harvested tem months after planting); E3: colheita realizada doze meses após o plantio (harvested twelve months after planting); and E4: colheita realizada quatorze meses após o plantio (harvested fourteen months after planting).

sos. Nos resultados obtidos e em qualquer época de colheita considerada no experimento, o acesso 4 destacou-se dos demais em produtividade. Doze meses após o plantio - época de colheita recomendada - a produção do acesso A4 foi $14,0 \%$ superior à produção do acesso A2; 29,8\% superior à produção do acesso A1; e 34,0\% superior à produção do acesso A3.

$O$ percentual de massa seca das raízes em relação à massa fresca foi, em média, $27 \%$ e é menor do que o encon-
Em E1, raízes colhidas oito meses após o plantio, a relação $\mathrm{MF} / \mathrm{MS}$ média era 4,1:1, caracterizando raízes ainda tenras, com maior conteúdo de água. Com o desenvolvimento da planta, o acúmulo relativo de biomassa deu início à redução na relação MF/MS que, em E3, raízes colhidas doze meses após o plantio, chegou a 3,3:1. Em E4, raízes colhidas quatorze meses após o plantio, houve um aumento na precipitação o que estimulou o desenvolvimento vegetativo e reprodutivo, provavelmente mobilizando as reservas acumuladas nas raízes e provocando uma conseqüente redução no peso de matéria seca (Tabela 2). Nesta época de avaliação, observou-se também um ligeiro aumento na produção de raízes, não significativo em relação à época anterior, com maior quantidade de raízes tenras. Porém, como estas raízes estavam na fase inicial desse desenvolvimento, sua massa não compensou as reservas mobilizadas e, com isso, houve redução na matéria seca, ainda que não significativa em relação à época anterior, e um ligeiro aumento na relação MF/MS.

Observou-se diferença significativa entre acessos e entre épocas de colheita em relação ao teor de $\beta$-ecdisona nas raízes de fáfia (Tabela 2 ). Os teores significativamente mais altos de $\beta$ ecdisona foram observados em raízes colhidas após oito $(0,36 \%)$, dez $(0,26 \%)$ e doze meses $(0,38 \%)$. Na $4^{\mathrm{a}}$ colheita, houve uma redução drástica no teor de $\beta$-ecdisona (0,16\%). Magalhães (2000), ao contrário dos resultados ora alcançados, não observou variação significativa no teor de $\beta$-ecdisona em colheitas realizadas com um ano de intervalo. Porém, os resultados do presente trabalho mostram a importância da determinação da estação do ano ou época ideal de colheita como função tanto da sazonalidade do teor de $\beta$-ecdisona, quanto da produção de biomassa.

Não só a época de colheita das raízes, mas também a origem genética do material de propagação interferiu significativamente no teor de $\beta$-ecdisona. Os acessos A2 (Querência do Norte, PR) e A3 (Taquaruçu, MS) apresentaram os teores de $\beta$-ecdisona significativamente mais altos $(0,37$ e $0,27 \%$, respectivamente), embora o valor alcançado pelo 
acesso A2 não tenha diferido dos demais (Tabela 2). Os teores de $\beta$-ecdisona encontrados neste trabalho, média geral de $0,29 \%$, são comparáveis aos valores relatados por Figueredo et al. (2002), que encontraram uma variação de 0,15 a $0,47 \%$, porém são inferiores à variação relatada em outros trabalhos, de 0,64 a 0,76\% (Nishimoto et al., 1990, Montanari et al., 1997, Marques, 1998). As diferenças entre os teores de $\beta$ ecdisona encontrados e os relatados podem ter sido causadas por fatores edafoclimáticos, genéticos e por diferenças na metodologia de extração e determinação.

\section{AGRADECIMENTOS}

A Dra. Marianne C. Scheffer, pelo incentivo e à excelente contribuição na elaboração deste trabalho. Ao Programa PR 12 meses, pelo apoio financeiro. Às universidades UEM e UNESP-Botucatu e à EMATER-PR, pela oportunidade e apoio na realização do trabalho.

\section{REFERÊNCIAS}

CORRÊA JÚNIOR C; MING LC; CORTEZ DAG. 2002. Aspectos gerais da espécie fáfia (Pfaffia glomerata Pedersen) e recomendações técnica para seu cultivo. Guatemala-Antigua. Anais... CYTED-Centro Iberoamericano de Formacion. Antigua,11p.
CORRÊA JÚNIOR C; CORTEZ DAG; MING LC; SOARES W. 2006. Fáfia - o ginseng brasileiro: aspectos agronômicos e fitoquímicos. Editora Clichetec Ltda, Maringá, 22p.

CORRÊA JÚNIOR C. 2003. Estudo Agronômico de fáfia [Pfaffia glomerata (Spreng.) Pedersen]: sazonalidade na produção de raízes e conteúdos de $\AA$-ecdisona em diferentes acessos de São Paulo, Paraná e Mato Grosso do Sul. Botucatu: UNESP-FCA, Depto. Horticultura. 93p. (Tese doutorado)

DINAN, L. 2001 Phytoecdysteroids: biological aspects. Phytochemistry 57: 325-339.

EMBRAPA. Centro Nacional de Pesquisa de solos (Rio de Janeiro). 1999. Sistema brasileiro de classificação de solo. Brasília: EMBRAPA. Rio de Janeiro: Embrapa solos, 412p.

FIGUEREDO LS; TEIXEIRA SL; FREITAS SP; VIEIRA IJC; MARTINS ER. 2004. Comportamento de 23 acessos de Pfaffia glomerata (Spreng.) Pedersen (AMARANTHACEAE), nas condições de Campo dos Goytacazes-RJ. Revista Brasileira de Plantas Medicinais 7: 67-72.

GARCIA I. 2000. O mercado para plantas medicinais em São Paulo: falta qualidade. Agroecologia hoje I: 30-38.

MAGALHÃES PM. 2000. Agrotecnologia para el cultivo de fáfia o ginseng brasileiro. In: Fundamentos de agrotecnología de cultivo de plantas medicinales iberoamericas. Bogotá: CYTED, p. 323-332.

MARQUES LC. 1998. Avaliação da ação adaptógena das raízes de Pfaffia glomerata (Spreng.) Pedersen-Amaranthaceae. São Paulo: USP, 145p. (Tese doutorado).

MONTANARI JR I; MAGALHÃES PM; QUEIROGA CL. 1999. Influences of plantation density and cultivation cycle in root productivity and tenors of b-ecdysone in Pfaffia glomerata (Spreng.) Pedersen. Acta Horticulturae 502: 125-128.
NISHIMOTO N; NAKAI S; TAKAGI N; HAYASHI S; TAKEMOTO T; ODASHIMA S; KIZU H; WADA Y. 1984. Pfaffosides and nortriterpenoid saponins from Pfaffia paniculata. Phytochemistry 23: 139-142.

NISHIMOTO N; SHIOBARA Y; INOUE S; TAKEMOTOA T; AKISUE G; OLIVEIRA F; AKISUE MK; HASHIMOTO G. 1990. Ecdisteroides de Pfaffia glomerata. In: Simpósio de Plantas Medicinais do Brasil, 11. 1990. João Pessoa, Pb. Anais... João Pessoa: Universidades Federais da Paraíba.

OLIVEIRA CMF. 1998. Estudo sobre a reprodução da fáfia [Pfaffia glomerata (Spreng.) Pedersen]. Curitiba:UFPR. 92p. (Tese mestrado).

RIBEIRO PGF; PEREIRA EF. 1994. Influência do método de propagação e tipo de solo na produção de raízes de fáfia (Pfaffia glomerata). In: SIMPÓSIO DE PLANTAS MEDICINAIS DO BRASIL, 13, Fortaleza. Anais... Fortaleza: FINEP/CNPq, 1994.

SHIOBARA Y; INQUE SS; KEATO K; NISHIGUCHI Y; OISHI Y; NISHIMOTO N; OLIVEIRA F; AKISUE G; AKISUE MK; HASHIMOTO G. 1993. A nortriterpenoid, triterpenoids and ecdysteroids from Pfaffia glomerata. Phytochemistry 32: 1527-1530.

SMITH LB; DOWNS RJ. 1998. Amaranthaceae. In: REITZ PR (Ed. 1). Flora Ilustrada Catarinense. Itajaí: Herbário Barbosa Rodrigues, $110 \mathrm{p}$.

VIGO CLS. 2004. Caracterização farmacognóstica comparativa da Pfaffia glomerata (Spreng.) Pedersen e Herbanthe paniculata Martius-Amaranthaceae. Revista Brasileira de Plantas Medicinais 6: 7-19. 